\title{
Questions Posed within Written Feedback in Clinical Education: A Research Note
}

\author{
Shannon Emmerson*, Gina Tillard, Tika Ormond, Ruth Ramsay and Brooke Moore
}

Department of Communication Disorders, University of Canterbury, New Zealand

\begin{abstract}
Clinical educators use a variety of methods to facilitate student development of critical thinking. One method is the use of effective questioning within written feedback. High level questions help to facilitate critical thinking by requiring the student to evaluate or make judgment on a clinical situation. As students progress through a continuum of competency from novice to graduate, the nature of feedback changes from directives to questions in response to the students' developing critical thinking abilities. This research notes details aspects in written feedback within a speech pathology educational setting. Novice students received lower level questions and more directives compared to advanced students. Suggestions for monitoring the ways in which questions are presented within written feedback are discussed.
\end{abstract}

Keywords: Clinical education, critical thinking, feedback, speech-language pathology, questions.

\section{INTRODUCTION}

Supervisors (often referred to as clinical educators) of students pursuing a profession in one of the health science disciplines use a variety of methods to facilitate student development of critical thinking. Critical thinking enables processing and analysis of information, solving of clinical problems, and decision making regarding an appropriate course of action [1]. The use of effective questioning can facilitate critical thinking [1-5]. When a student is presented with effective questions they are then required to engage in problem-based learning and in turn a critical thinking learning experience [6]. Studies have looked at what types of questions have been used to facilitate critical thinking. There are a variety of question types that can be ranked in hierarchy. This ranking is related to the level of cognitive processing. A variety of terminology is used to describe the types or hierarchy of questions used, for example, Socratic questions (open questions [1]); Bloom's taxonomy (knowledge, understanding, application, analysis, synthesis, evaluation [2, 7]); high level questions (problem-solve, analyse and evaluate) and low level questions (factual, recall $[8,9])$. The theme amongst these descriptions of questioning is that those types of questions higher-up the hierarchy are more cognitively challenging and require evaluation and analysis to occur, compared to lower level questions that simply rely on recall and are factual.

High level questions help to facilitate critical thinking by requiring the student to evaluate or make judgment on a clinical situation. In order to answer high level questions appropriately, students are required to rationalise their views as there are potentially multiple possibilities to the questions posed [1]. For example, a student may need to justify why a specific clinical approach is most beneficial for a particular

*Address correspondence to this author at the Department of Communication Disorders, University of Canterbury, Private Bag 4800, Christchurch, 8140 New Zealand; Tel: +64 3366 7001, Ext. 7304; Fax: +64 3364 2760; E-mail: shannon.emmerson@canterbury.ac.nz client by providing specific examples and clinical reasoning to support this decision. Clinical practice is a setting that provides many opportunities to enable and promote critical thinking by means of questioning [5].

Clinical educators may pose high level questions within oral or written supervisory feedback to facilitate critical thinking. Feedback has a significant influence on student's achievements and development $[10,11]$ and the provision of this is a key role of a clinical educator [12]. The clinical educator will determine whether oral or written or a mixture of the two forms of feedback is most beneficial for each student. Written feedback refers to the supervisor recording their impressions regarding students' observed performance [13]. Oral feedback is the provision of spoken information based on the student's clinical performance. This is intended to weaken or strengthen aspects of the learner's behavior, thoughts or feelings [14]. Oral feedback allows open discussions to occur within the moment, results in immediate responses to high level questioning, and reduces the likelihood of ambiguity occurring. Providing written feedback has the benefit of allowing both the student and the clinical educator to review their comments at a later date, to demonstrate progress, and to ensure that advice and questions have been followed. It is recognised that at different stages in a training programme students require different levels and styles of feedback to facilitate critical thinking $[12,15,16]$.

As students progress through a continuum of competency from novice to graduate, the nature of feedback changes from directives to questions in response to the students' developing critical thinking abilities [16, 17]. Students' needs change as they progress through their training, as noted in Anderson's Continuum of Supervision [17], and in turn the level and type of feedback changes in accordance to those changing needs as they progress through their clinical practice. Following this model, clinical educators initially take a more directive role and then progress to a more consultative role. This is due to students requiring a higher level of input and instruction whilst in their novice stage of 
clinical development. Advanced students however, require less specific direction and may be presented with a variety of questions to guide their clinical learning. Evidence of the clinical educator's ability to adapt feedback between advanced and novice students can be identified within the written feedback provided to the two groups.

Currently, there is a lack of research in the field of speech-language pathology clinical education regarding the use of written feedback and how this form of feedback may facilitate critical thinking. Reflecting on the expectations and experiences of being a clinical educator will enhance the educational experience for both the clinical educator and the students. It is important that clinical educators actively seek ways in which to enhance the educational experience for their students and to further develop their clinical education skills. This current research note adds to the literature regarding the use of feedback within the clinical education setting and provides examples of written feedback used by clinical educators in speech-language pathology. Evidence of working through Anderson's Continuum of Supervision [17] can be found within the feedback. As per the past results of Martin [16] and Anderson [17] it was hypothesised that advanced students would be provided with less directive comments, fewer instructions and a higher number of questions. It was also hypothesised that of those questions posed, advanced students would receive a greater number of high level questions compared to novice students.

\section{METHOD}

\section{Participants}

The data for this research were derived from the written feedback provided by a Speech-Language Pathology Clinical Educator at the University of Canterbury (Christchurch, New Zealand). Written feedback was provided to eight undergraduate speech-language pathology students during on-campus clinical placements as part of their clinical supervision expectations. The group of eight students included six novice level speech-language pathology students (in their $1^{\text {st }}$ year of the professional programme and $2^{\text {nd }}$ academic year at university) and two advanced speechlanguage pathology students (in their $3^{\text {rd }}$ and final year within the professional programme and $4^{\text {th }}$ academic year at university). The students were selected based on available students in the speech-language pathology programme. No attempt was made to select students on the basis of motivational or psychological features. The novice students received written feedback over a 12-week part-time placement. This was their first experience working with clients and resulted in an accumulation of approximately 30 hours of face-to-face client contact. The written feedback provided to the advanced students was over a six-week parttime clinical placement, resulting in students gaining approximately 30 hours of face-to-face client contact. This placement was the students' penultimate clinical placement prior to completion of their degree. The advanced students were also involved in mentoring the novice students through their clinical experience. This role of mentor involved modeling clinical skills within sessions and discussing aspects of client management.

\section{Procedure}

Written feedback was provided by the clinical educator to each student immediately after each of their clinical sessions. A clinical session was defined as the face-to-face time the student spent with a client targeting communication goals and was usually between 60 and 90 minutes in duration. At the time of this feedback being provided, the clinical educator was not aware of (i.e. "blinded to") the research goals of the study. Research relating to critical thinking and this current data was analysed retrospective to the feedback being provided. The feedback was provided in a clinical log book assigned to each student clinician. Oral feedback and discussion was also provided, however only the written feedback was analysed in this study. Written feedback was reviewed for content and divided into idea units. An idea unit was defined as a complete statement, ending with a comma, period, or 'and' [18], i.e. a t-unit, which is an independent clause and any associated dependent clauses [19]. These idea units were then segmented into three categories: questions (i.e. sentences that seek information), instructions (i.e. directive sentences) and comments (i.e. conveys information) [20]. The first author independently segmented the written feedback transcripts into idea units and categories. The reliability of segmenting the transcripts was evaluated by having another speech-language pathology clinical educator independently separating $20 \%$ of the transcripts. These results were then compared to the first author's transcripts. An inter-rater correlation of $r=.96$ was obtained.

\section{Analysis}

Written feedback idea units were analysed by allocating the idea units into the three categories of questions, instructions and comments. Questions were then separated into 'High Level' and 'Low Level' questions, according to Brualdi [8] and Oermann [9].

\section{RESULTS}

\section{Feedback Categories}

A total of 644 idea units were analysed that included questions, comments and instructions. The frequency of use of questions, instructions, and comments were identified in the written feedback and converted to percentage scores for the two levels of student ability (novice and advanced). A chi-square test showed that the advanced students received significantly more questions than the novice students (see Fig. 1), $x^{2}=12.05, d f=1, p<.01$. This result confirms the original hypothesis that advanced students would receive a higher number of questions within their written feedback than novice students. Also as hypothesised advanced students received significantly fewer comments than novice students, $x^{2}=19.00, d f=1, p<.01$. Interestingly, the advanced students received a significantly higher number of instructions than the novice students, $x^{2}=4.59, d f=1, p=$ 0.03. This runs counter to the view of Anderson [17]. The level of instruction may be influenced by the students' experience with the client group rather than the overall level of experience or total number of practice hours accumulated. This result may also be due to the format of the current 
clinical environment, where the advanced students were provided with additional feedback and instructions pertinent to their mentoring status, compared to the novice students receiving feedback purely in relation to their clinical interactions with their clients.

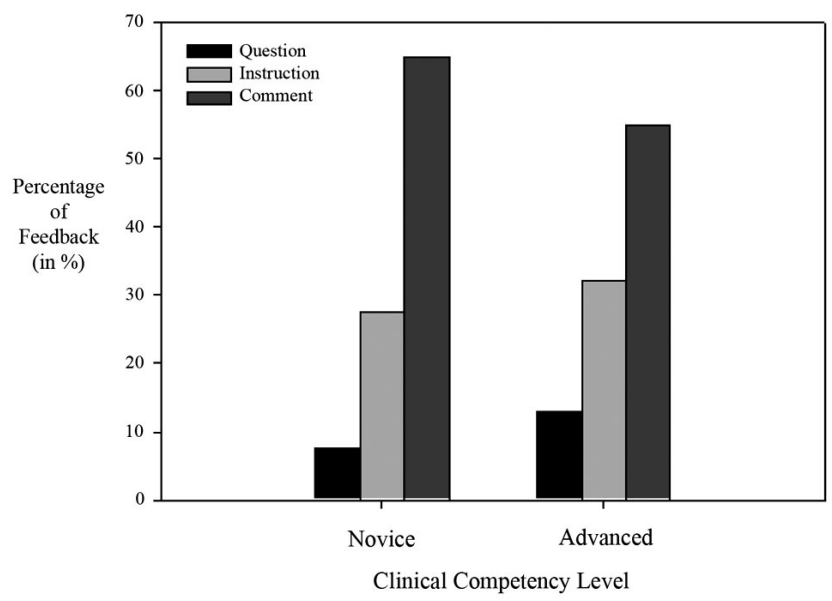

Fig. (1). Percentage of statements, instructions and questions provided in written feedback to novice and advanced students.

The frequency of high and low level questions were identified and converted to percentage scores for the two levels of student ability. The results of this analysis are provided in Fig. (2). A chi-square test showed that advanced students received significantly more high level questions compared to the novice group, $x^{2}=9.38, d f=1, p=<.01$. Examples of questions used within the written feedback for each group included:

High Level Questions: 'How did your discussion regarding goals go?' (novice); 'Do you think there are ways in which you can increase your client's lead in activities?' (novice); 'How could you assist comprehension for some clients in the group discussion?' (advanced); 'What could you do to cue?' (advanced).

Low Level Questions: 'Did you have enough activities?' (novice); 'Did you notice the client's stuttering decrease during one-on-one?' (novice); 'Do you notice your client vocalising?' (advanced); 'Do you notice how your client seeks praise?' (advanced).

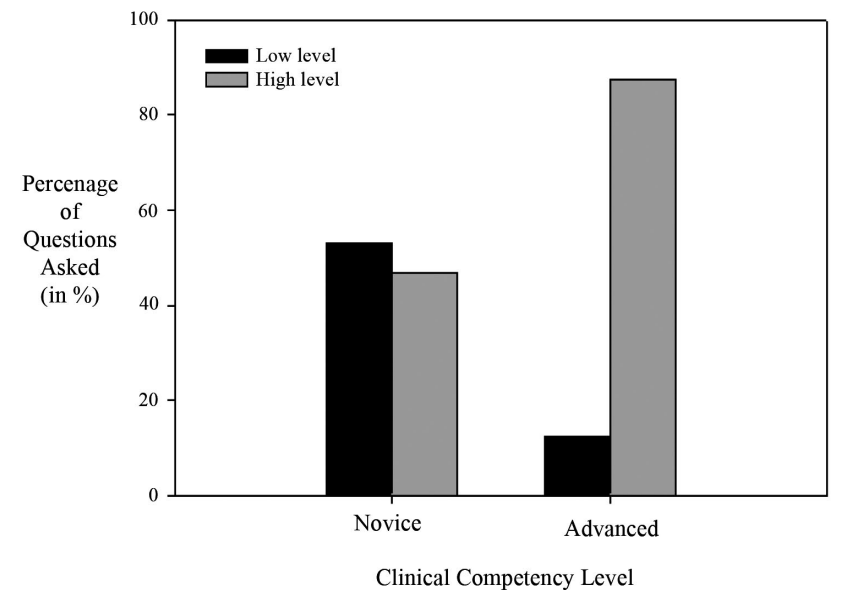

Fig. (2). Percentage of low and high level questions posed to novice and advanced students in their written feedback.

\section{DISCUSSION}

This result confirms the hypothesis that advanced students would receive a greater number of high level questions compared to novice students. In accordance to Brualdi [8] and Oermann [9] the use of high level questioning is identified as facilitating critical thinking, therefore it may be presumed that the advanced students were required to utilise critical thinking more often than the novice level students. This finding corresponds to Martin's Theory of Critical Thinking [16], which suggests that students' critically thinking experiences increase as they progress through their learning and that they become more proficient at using critical thinking skills due to increased knowledge and experience. These results could be used to infer that the clinical educator was facilitating critical thinking at an appropriate level for the groups reviewed.

It is important for clinical educators in the field of speech-language pathology and other health professionals to reflect on the means by which they facilitate critical thinking in their students and to ensure that they are targeting this at an appropriate level. Methods include problem-based learning [6, 18, 21-23], presenting high level questions [1-5], debates and media clips [1]. Studies have found that students respond positively to critical thinking exercises [21, 22]. It is the responsibility of the clinical educator to ensure that they are facilitating critical thinking in the most appropriate manner in order to enhance student's motivation. Hyland [24] suggested that interviewing student's after receiving written feedback was a useful manner in which to evaluate student's motivation and responses to written feedback. This idea of valuing the student's perception and response to feedback could also be used with regards to how critical thinking is facilitated. Focus group discussions could occur in the initial, medial and final stages of students' placements to ensure that the method in which critical thinking was being facilitated was motivating and beneficial for the students.

As identified in this study, the use of written feedback provides a means in which the clinical educator can selfmonitor the level and type of questions that are being presented to their students. Clinical educators can check that they are indeed using high level questions to promote critical thinking and that their frequency is appropriate according to the student's competency level. Based on Bloom's taxonomy of questions [2,7] a clinical educator can check if the questions are relating to application, analysis, synthesis, or evaluation (high level questions) as opposed to only using low level questions relying on factual knowledge of clinical concepts or competency. A list of examples could be referred to when reviewing feedback or perused prior to providing written feedback to provide ideas on how to present high level questions in a variety of ways. It is important to selfmonitor and reflect on our own skills $[12,25]$ in order to ensure that we are effective in our role of clinical educators.

\section{STUDY LIMITATIONS}

It is important to acknowledge that the sample size considered in this study was small. As such, generalisations from the findings are limited and should then be considered preliminary. Still, the results clearly support past research examining the role of question-type to facilitate critical 
thinking. It would be optimal to reproduce this study with a larger number of students and clinical educators.

\section{FURTHER RESEARCH}

Future exploration would be useful in the area of speechlanguage pathology clinical educator feedback within a range of health discipline settings. This would identify similarities and differences between styles of written feedback with the aim of then developing a consistent approach to maximize the effectiveness of questions in feedback to develop critical thinking. It would also be of interest to compare feedback across clinical education settings in a variety of health disciplines, for example physiotherapy, nursing, and occupational therapy. The student's response and attitude towards feedback would be another valuable aspect to investigate. Hyland [24] proposed that the use of an interview would be an appropriate manner in which to gain insight into the benefits of written feedback from the student's perspective. Interviews would need to take place within a day of receiving the feedback to allow time for the students to process and evaluate the usefulness of the feedback. Another avenue with regards to the follow-up of feedback could be tracking the process of the questions asked, how the student responds to this within their reflection, and how the clinical educator then provides further feedback on the critical thinking process. This research would involve reviewing the entire process of facilitating critical thinking within written feedback and analysing the cohesion of the process and the student's experience.

\section{CONCLUSION}

Students have different learning needs and it is important that these are identified in order to promote engagement and motivation [26]. The timing and frequency of feedback needs to be established collaboratively between clinical educators and their students. In the present study, high level questions were more predominant in written feedback provided to more experienced students. Clinical educators need to determine what method of facilitating critical thinking is most beneficial for their students and then utilise resources available to them to enhance such skills.

\section{REFERENCES}

[1] Oermann M, Truesdell S, Ziolkowski L. Strategy to assess, develop, and evaluate critical thinking. J Cont Educ Nurs 2000; 31 (4): 155-60.

[2] Gall MD. The use of questions in teaching. Rev Educ Res 1970; 40 (5): 707-21

[3] Malek C. A model for teaching critical thinking. Nurs Educ 1986; 11(6), 20-3

[4] Marcisz N, Woien S. A case study: Enhancing critical thinking skills in an online health care ethics course. J Online Learn Teach 2010; 6 (2): 466-74
[5] Myrick F, Yonge O. Preceptor questioning and student critical thinking. J Prof Nurs 2002; 18 (3): 176-81.

[6] Mok CK, Whitehill TL, Dodd BJ. Problem-based learning, critical thinking and concept mapping in speech-language pathology education: a review. Int J Speech Lang Pathol 2008; 10(6): 438-48.

[7] Howard RA, Carver CA, Lane WD. Felder's learning styles, Bloom's taxonomy, and the Kolb learning cycle: tying it all together in the CS2 course 1996; 28(1). Available from: http://portal.acm.org/citation.cfm?id=236545 [Retrieved 2011 Feb 7].

[8] Brualdi AC. Classroom questions. Pract Assess Res Eval 1998; 6(6). [Retrieved 2011 Feb 3]. Available from: http://PAREonline. net/getvn.asp? $\mathrm{v}=6 \& \mathrm{n}=6$

[9] Oermann M. Ideas for postclinical conferences. Teach Learn Nurs 2008; 3: 90-3.

[10] Gillam RB, Roussos CS, Anderson JL. Facilitating changes in supervisees' clinical behaviours: an experimental investigation of supervisory effectiveness. J Speech Hear Disord 1990; 55: 729-39.

[11] Hattie J, Timperley H. The power of feedback. Rev Educ Res 2007; 77 (1): 81-112..

[12] McAllister L, Lincoln M. Clinical education in speech-language pathology. London, England: Whurr Publishers 2004.

[13] Ho DWL, Whitehill T. Clinical supervision of speech-language pathology students: Comparison of two models of feedback. Int $\mathrm{J}$ Speech Lang Pathol 2009; 11 (3): 244-55.

[14] Milne DL, James IA. The observed impact of training on competence in clinical supervision. Br J Clin Psychol 2002; 41: 5572.

[15] Bartlett DJ, Cox PD. Measuring change in students' critical thinking ability: Implications for health care education. J Allied Health 2002; 31 (2): 64-9.

[16] Martin C. The theory of critical thinking of nursing. Nurs Educ Perspect 2002; 23 (5): 243-7.

[17] Anderson JL. Supervisory Process in Speech-Language Pathology and Audiology 1988. In: Gillam RB, Roussos CD, Anderson JL, Eds. Facilitating changes in supervisees' clinical behaviours: an experimental investigation of supervisory effectiveness. J Speech Hear Disord 1990; 55: 729-39.

[18] Yew E, Chng E, Schmidt H. Is learning in problem-based learning cumulative? Adv Health Sci Educ 2010, Dec 3 [Retrieved 2011 Feb 7]. Available from: http://metapress.com/content/4q58967p15 10228/fulltext.pdf

[19] Foster-Cohen S. An Introduction to Child Language Development New York, USA: Addison Wesley Longman 1999.

[20] Crystal D. Rediscover Grammar. London, England: Pearson Education Ltd 1996.

[21] Cooke M, Moyle K. Students' evaluation of problem based learning. Nurs Educ Today 2002; 22: 330-9.

[22] MacKinnon M. CORE Elements of Students Motivation in Problem-Based Learning. New Dir Teach Learn 1999; 78: 49-58.

[23] Stokes SF, MacKinnon MM, Whitehill TL. Students' experiences of PBL: Journal and questionnaire analysis. Aust J High Educ 1997; 27 (1): 161-79.

[24] Hyland F. The impact of teacher written feedback on individual writers. J Second Lang Writing 1998; 7 (3): 255-86.

[25] Weaver MR. Do students value feedback? Student perceptions of tutors' written feedback responses. Assess Eval High Educ 2006; 31(3): 379-94.

[26] Seibert DC. Secrets to creating effective and interesting educational experiences: Tips and suggestions for clinical educators. J Genet Couns 2008; 17: 152-60.

This is an open access article licensed under the terms of the Creative Commons Attribution Non-Commercial License (http: //creativecommons.org/licenses/by$\mathrm{nc} / 3.0 /$ ) which permits unrestricted, non-commercial use, distribution and reproduction in any medium, provided the work is properly cited. 